\title{
Advantages and Challenges of Cooperative Learning in Two Different Cultures
}

\author{
Mohammad Reza Keramati ${ }^{1}$, Robyn M. Gillies ${ }^{2}$ \\ Faculty of Education and Psychology, University of Tehran, Tehran, Iran 1; mkeramaty@ut.ac.ir \\ 2 Robyn M. Gillies, School of Education, Professor at University of Queensland, Brisbane, QLD, Australia 2; \\ r.gillies@uq.edu.au \\ * Correspondence: mkeramaty@ut.ac.ir; Tel.: 0989124932306
}

\begin{abstract}
Cooperative learning (CL) is a teaching and learning pedagogy that has been used widely in school but there is limited information on instructors' perceptions of CL nor observations of how $\mathrm{CL}$ is implemented in higher education settings. In this study, we investigated the advantages and challenges of embedding CL into instructors' teaching in Iran and Australia. Data were collected through interview and observation. Results showed that despite challenges such as the lack of familiarity of CL and how it can be implemented in university curricula, issues associated with assessment, and time constraints, CL created an interactive, pleasant and safe environment for deep learning in both countries. The findings showed that there were challenges in Iran such as a tendency to use traditional approaches to teaching, insufficient understanding of how to establish teamwork, and a lack of up-to-date teaching resources. In Australia, changing courses, working with external students, catering for individual differences, and building positive relationships were some of the challenges of implementing CL. We believe that these challenges can be overcome if university instructors are prepared to address them.
\end{abstract}

Keywords: Australia, cooperative learning, Iran, quality of implementation, university instructor

\section{Introduction}

Cooperative learning (CL) is defined as small groups where students work together to maximize their own and each other's learning [1], and, in so doing, promote a variety of positive cognitive, affective, and social benefits [2]. CL is based on the theoretical perspective of social interdependence theory which proposes that when students are interdependently connected, they will cooperate with each other to realize their group goal [3]. CL is an effective pedagogy [4] that is used to foster learning [5,6], and critical thinking skills [7]. It can also be used to help develop students' communicative abilities [8], improve self-regulated learning and promote academic motivation [9]. Barksdale, Peters, and Corrales [10] noted that student learning is influenced by the relationships that they build with each other so when students feel safe and supported in their classroom, learning is enhanced. Other studies show that CL provides such a safe environment that as students have opportunities to collaborate with others, knowledge is socially constructed and relationships are built [11]. Instructors play a critical role in promoting dialogic interaction in their students [12] so students learn how to ask questions, make clear their ideas, and assess the viability of the issues they are discussing [13]. Setting clear instructions and task expectations play an essential role in the effective implementation of CL [14]. Kohn [15] believes that if the tasks assigned to the groups are interesting and attractive, CL itself is a type of reward for students and instructors. 
In colleges, students are often required to work together in small groups, based on activities such as seminars, presentations, and group projects. Research indicates that such activities not only provide learning opportunities that capture students' interest but also lead to enhancing their learning $[16,17]$. Making learning more meaningful, inspiring ownership and commitment to tasks [18], and developing a commitment to fairness and social responsibility [19] are other benefits that have been documented. Inquiry-based teaching and learning approaches seem to play an important role in developing the spirit of cooperation in the classroom [20].

Despite the benefits widely attributed to a cooperative approach to learning compared to the individualistic approach [21,22] many instructors struggle with applying it in their classes [23], with some believing it is challenging to implement [24]. Challenges include dependence on others for solutions [25], the lack of time provided in the curriculum [26,27] and students' lack of skills needed to cooperate [28]. These challenges can be minimized by teaching skills such as actively listening to each other, sharing ideas and information, providing help to others, sharing leadership and planning roles [29], and also dialogic teaching [12]. In CL classrooms, the basic challenge shifts from learning in the conventional sense to the construction of collective knowledge [30]. Hakkarainen [31] argued that knowledge advancement is not just supporting the students' ideas but it is also working with knowledge. Other challenges include class size [32], and instructors' knowledge of the process [33]. Interestingly, Nguyen-Phuong [34] found that individual differences are not a threat and actually enhance group productivity.

Previous studies have documented the advantages of CL [35,36,23,3,37], but few studies have specifically studied the advantages and challenges of CL from the university instructors' perceptions. However, given the benefits widely attributed to CL when it is implemented in school settings $[38,39,40]$, investigating its potential benefits in university settings seems warranted. Furthermore, while almost all research supports the benefits of CL in western education, little research appears to have been conducted in other countries with different social, religious, education, and cultural systems [41]. Although the study of learning environments of schools in Australia and Taiwan was a good starting point, such comparative studies of university learning environments in Australia with other countries have also received less attention [42], especially in Middle Eastern countries such as Iran. In the current qualitative study, we as researchers from Iran and Australia sought to explain the differences and similarities between the CL environments in the two countries and this feature distinguishes the present study from other studies. We combined university instructors' perceptions of CL with data from classroom observations in two distinctly different countries to achieve a more comprehensive understanding of the pedagogical practices that were employed within a given cultural context [34], and this is a distinctive feature of the present study.

\section{Materials and Methods}

A case-study design with an interpretative-qualitative approach was used. Nine instructors in the Faculty of Psychology and Education at the University of Tehran (UT) in 
Iran and ten instructors in the School of Education at the University of Queensland (UQ) in Australia were invited to participate in interview. The criteria used to assess involvement included: implementation of CL in the class, and willingness to participate in an interview. Participants were 4 males and 5 females at the UT, and 4 males and 6 females at the UQ. Five instructors from each university agreed that their classroom could be observed. The average interview time for each interviewee was 55 minutes. Semi-structured interviews and classroom observations were conducted by an instructor at the UT in March, April, and May 2019, and at the UQ in September, October, and November 2019. Interview questions were open-ended allowing the participants to contribute additional information as they saw fit:

1. What do you think CL is? Describe one concrete example, as specifically as possible.

2. What advantages do you think you would observe if you were to use CL in your classroom?

3. What challenges do you think you would face if you were to use CL in your classroom?

At the UT, the interviewer met with the instructors after the interviews had been transcribed to ensure that the transcripts correctly represented what was discussed in the interviews. He also met with the participants after the interviews had been coded to indicate what themes emerged from the interviews to see if the participants agreed or disagreed with this analysis. Once the interviews were transcribed, the researchers contacted the participants and followed-up with each participant on whether the transcriptions correctly captured what the participants had discussed in the interview. At the UQ, an Australian instructor transcribed the content of the interviews, and then the authors reviewed the interview file and typed the text several times to minimize possible errors in transcribing the interviews. Observations were undertaken totalling 20 sessions per university. The observer was first informed of the class time and location by the instructor. The instructor introduced the observer to the students and then he participated in the groups as a group member and interacted closely with them as a "complete participant" [43]. According to Anderson [44] this provides access to a wide range of data because people feel that they are dealing with a friend or colleague, not a researcher, and as a result, the observed behaviour is more explicit and honest. In the present study as the observer interacted, he wrote down his observations of that class. The observer discussed his field notes with the instructors and with the co-author of the current article after each lesson. After these discussions, some statements were removed and some of them were revised. A standard protection for participants is often the guarantee of confidentiality and privacy, withholding participants' real names and other identifying characteristics [45]. Participants at both universities were de-identified and given a unique ID number. The researchers discussed the research with the participants before the research commenced and after the data were collected. Participants were assured that their personal information was protected. They were required to sign a consent form indicating that they understood the purpose of the study, the requirements for data collection, the protection of confidentiality, and their right to withdraw at any stage. 


\section{Results}

We listened to the recorded files, transcribed the recorded data and then read it several times. At this stage, as the ideas emerged, the initial codes were formed. We refined themes several times to place sub-themes within main themes based on their similarities. We grouped the various statements that emerged from the interviews and observations into six themes. We also identified the total number of times the topic of the interviews and observations was discussed (Table 1, 2).

Table 1. Advantages of CL in UT and UQ

\begin{tabular}{|c|c|c|c|c|c|c|c|c|}
\hline \multirow{4}{*}{$\underset{\mathscr{E}}{\stackrel{\mathscr{E}}{E}}$} & \multicolumn{3}{|c|}{ Sub-themes } & \multicolumn{4}{|c|}{ Number of references ${ }^{a}$} & \\
\hline & \multirow{3}{*}{$\begin{array}{l}\text { Similarities } \\
\text { UT and UQ }\end{array}$} & \multicolumn{2}{|c|}{ Differences } & & & & & \\
\hline & & \multirow[t]{2}{*}{ UT } & \multirow[t]{2}{*}{ UQ } & \multicolumn{2}{|c|}{ Interview } & \multicolumn{2}{|c|}{$\begin{array}{c}\text { Observa- } \\
\text { tion }\end{array}$} & \multirow[b]{2}{*}{ Total } \\
\hline & & & & $\mathrm{UT}$ & UQ & $\mathrm{UT}$ & UQ & \\
\hline 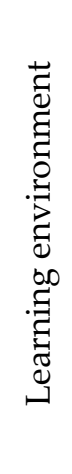 & $\begin{array}{c}\text { Interactive } \\
\text { environment, } \\
\text { pleasant en- } \\
\text { vironment, } \\
\text { safe envi- } \\
\text { ronment }\end{array}$ & - & $\begin{array}{l}\text { High motiva- } \\
\text { tion of in- } \\
\text { structors to } \\
\text { teach and } \\
\text { engage stu- } \\
\text { dents in } \\
\text { classroom } \\
\text { discussions, } \\
\text { optimal use } \\
\text { of resources }\end{array}$ & 18 & 30 & 24 & 44 & 116 \\
\hline 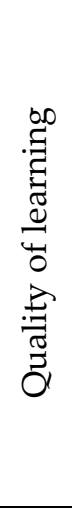 & $\begin{array}{c}\text { Deep learn- } \\
\text { ing, solving } \\
\text { complex } \\
\text { problems, } \\
\text { developing } \\
\text { the students' } \\
\text { understand- } \\
\text { ings and } \\
\text { knowledge }\end{array}$ & - & - & 20 & 25 & 14 & 24 & 83 \\
\hline Tota & & & & 38 & 55 & 38 & 68 & 199 \\
\hline
\end{tabular}

"Reference" refers to the total number of times the topic of the interviews and observations was discussed.

Table 2. Challenges of CL in UT and UQ

\begin{tabular}{|c|c|c|c|c|c|}
\hline \multirow{4}{*}{$\begin{array}{l}\stackrel{\mathscr{Q}}{E} \\
\stackrel{\mathscr{Q}}{E}\end{array}$} & \multicolumn{3}{|c|}{ Sub-themes } & \multicolumn{2}{|c|}{ Number of references ${ }^{a}$} \\
\hline & Similarities & \multicolumn{2}{|c|}{ Differences } & & \\
\hline & UT and UQ & UT & UQ & Interview & $\begin{array}{l}\text { Observa- } \\
\text { tion }\end{array}$ \\
\hline & & & & UQ & UT UQ \\
\hline
\end{tabular}




\begin{tabular}{|c|c|c|c|c|c|c|c|c|}
\hline$\frac{\Xi}{\Xi}$ & $\begin{array}{l}\text { Time con- } \\
\text { straints, } \\
\text { grading sys- } \\
\text { tem }\end{array}$ & $\begin{array}{l}\text { Inflexibility } \\
\text { of rules, re- } \\
\text { stricted } \\
\text { seating ar- } \\
\text { rangements }\end{array}$ & $\begin{array}{l}\text { Changing } \\
\text { courses, } \\
\text { working with } \\
\text { external stu- } \\
\text { dents }\end{array}$ & 34 & 36 & 11 & 14 & 95 \\
\hline 节 & - & $\begin{array}{c}\text { gender, in- } \\
\text { sufficient } \\
\text { knowledge } \\
\text { of team- } \\
\text { work, lack } \\
\text { of student's } \\
\text { motivation, } \\
\text { unequal } \\
\text { opportunity } \\
\text { for partici- } \\
\text { pation, } \\
\text { non-curricul } \\
\text { um discus- } \\
\text { sions }\end{array}$ & $\begin{array}{l}\text { Catering for } \\
\text { individual } \\
\text { differences }\end{array}$ & 19 & 14 & 9 & 8 & 50 \\
\hline
\end{tabular}

Classroom

ธั management, the lack of $\leftrightarrows$ familiarity of

CL

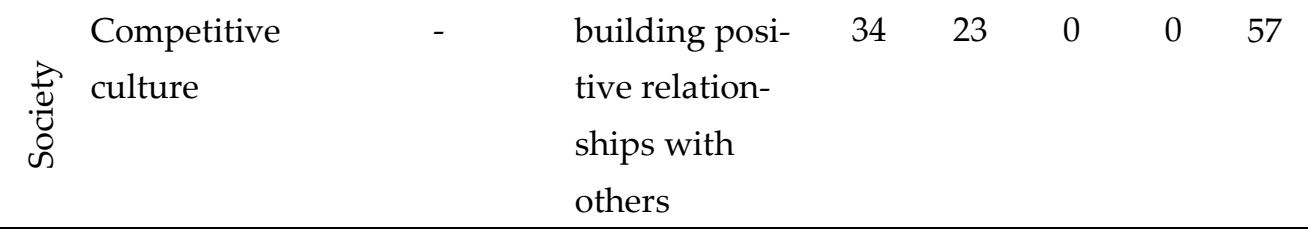

\begin{tabular}{lllllll}
\hline Total & 98 & 89 & 48 & 49 & 286
\end{tabular}

" discussed.

\subsection{Advantages}

\subsubsection{Learning environment}

Participants' perceptions and classroom observations showed that the interactive, pleasant and safe environment is an important advantage of CL in Iran and Australia. The following comments highlight the importance the Iranian participants (IP) attached to the CL environment:

Through teamwork in the CL classroom, students supervised each other's work and felt responsible for each other's learning (IP 1).

Although my lesson is more theoretical, the classroom environment has become more attractive since I implemented CL in the classroom (IP 9). 
I used to teach by lecturing in my classes. I saw the stress of the students in class. But since I teach in a cooperative way, students come to class calmly and enthusiastically, without stress and fear, and do not like to be absent (IP 4).

Some students told me that they are quiet in most classrooms and are ashamed to speak in public, but they speak easily in CL class (IP 3).

Similar comments were made by the Australian participants (AP):

CL challenges people to interact in ways that they don't often think are synonymous with formal education, and so being able to negotiate with someone to achieve a common goal (AP 5).

We are seeing more stress and mental health problems in our student community. I think that the competition makes that worse. It's a safer environment for students if it's cooperative rather than competitive (AP 2).

I found that students relax and they assist each other on their assignments (AP 4).

$C L$ is catering for diversity, and fostering democracy or inclusive environments ( $A P$ 1).

Our observations in Iran showed that interaction between the instructor and the students as well as the interaction between the students with each other were very positive and energizing. The classes were peaceful and harmonious with no one exhibiting stress. Some students reported that group work was interesting as it introduced them to different ideas and perspectives. In the 5 classes we observed in Australia, the seating arrangements were circular which automatically facilitated interaction, however, interactions appeared to be were less challenging and more consensual. Instructors were very motivated, and made optimal use of resources available in the classroom.

\subsubsection{Quality of learning}

Participants believed that a CL class would improve the quality of students' learning. Although the statements are slightly different in the two countries, all concurred that there were benefits when this approach to teaching was implemented. For example, the UT participants believed that CL could create a vision for working together, introduce students to different perspectives, as well as provide opportunities to solve more complex problems:

One of the advantages of CL is that it allows students to think more creatively and try to provide stronger and better analytics in the group, and also permits students to look at subject matter from different perspectives (IP 8).

In the CL class, everyone in the groups expresses their opinions, and this makes the students more aware of different opinions (IP 6).

Students have more opportunities to challenge each other's ideas during teamwork (IP 2).

CL is effective in terms of solving critical problems (IP 5).

Students are more confident in solving difficult subject matter in the group (IP 7).

Similarly, UQ participants believed that CL could improve the quality of learning by pre- 
senting new ideas, and different perspectives, leading to the development of knowledge as well as providing opportunities to solve more complex problems:

CL builds relationships, exposes students to new ideas and different perspectives, helps students think more deeply about phenomena, gives me a break from talking! (AP 8)

One of the key things about CL, is that you get to the root, you engage in a far deeper discussion, because you're creating ideas, you are adding onto your friends' ideas, you are also looking at it from different perspectives (AP 4).

It is active construction of knowledge as participants seek to build upon one another's understandings of the particular issue (AP 6).

$C L$ is advantageous in terms of solving complex problems (AP 10).

You know getting people to solve complex problems and you have some belief that four heads are better than one (AP 1).

In the 5 UT classes, the students' concentration was high, and the questions asked by the instructor were challenging, however, group cohesion would have been better if all students had participated equally in the discussions. Classroom management and instructor supervision could have been better. In the UQ classes, the questions that were asked were challenging, but there was little challenge between the groups. Each group only presented its own report with the other groups refraining from critiquing each other's views. Deep learning conditions were available, but synergy between members led to fewer new ideas.

\subsection{Challenges}

\subsubsection{Curriculum}

For most of the participants, lack of time is one of the challenges of CL. For example, three UT participants said:

At university, well, there's so little time, and so much emphasis on syllabus (IP 5).

In CL class, content may not be well understood due to lack of time (IP 7).

In CL class, grouping and group reporting is time consuming and as a result the learning opportunity is lost and the instructor cannot draw conclusions (IP 8).

And two UQ participants commented:

At university, well, the devil is always time, because courses are always crammed and there's very little time (AP 9).

For me, time is a challenge. Two hours weekly teaching time may not be sufficient, because even if you don't want to share the content with the students you have to contribute to students understandings of the concepts (AP 6).

At UT, the syllabus is pre-determined and instructors thought they could teach more content through lectures. However, concern was expressed about the lack of time, particularly when some sessions were not held due to air pollution or different religious 
occasions. At UQ, instructors started and finished the class on time. After class, they took the time to answer students' questions. They presented the material themself and in a separate session devoted time for presentations by student teams. The grading system in Iran is one of the most important challenges in implementing CL. We chose two quotations to show the dimensions of the challenge:

As you know, the UT is the largest university in Iran and the competition for admission to this university is fierce. At university, we also see some competition for a high mark. Therefore, creating a positive dependence is difficult to implement CL effectively (IP 2).

In the end, the university asks me to record a mark of 0-20 for the student in the system. To encourage students to group work, it is essential to assign a portion of the score to group performance, but in practice there are problems. The student's concern about the score is one of these problems. Therefore, if the evaluation is descriptive, CL can be implemented better (IP 7).

Similarly, in Australia, grading was also an important challenge for implementing CL. The statements of three participants show the nature of this challenge:

Whereas when things are graded, and our students here now at UQ are very competitive. Getting good grades are very important for them (AP 2).

I think there's a perception that grading and hierarchies; you're a 'high distinction', or a 'distinction' is seen as an important part of the university education (AP 10). There are students who are worried about their assessment (AP 1).

Participants in Iran refer to the inflexibility of the rules as a challenge. One of them said:

Inflexible rules hinder the effective implementation of CL. For example, one of these rules is teaching based on sylubus approved by the Ministry of Higher Education. Another rule is the 0-20 grading system, which makes it difficult to evaluate teamwork (IP 7).

And IP 3 as he shifted in his chair, he said:

Sometimes it's hard to satisfy the university leaders regarding the usefulness of CL.

Unlike UT participants, who cited inflexibility as a challenge, UQ participants spoke about continuous change of the courses as a challenge. For example AP 1 said:

Many of the courses here are changing, but I'm not sure to what effect, because I don't know to what extent different models of teaching a course have changed.

And AP 2 said: 
Sometimes it's hard to convince the Head of School and of course all of our processes to change a course to make it 'different'.

Most participants in UT stated that the non-circular positioning of the chairs hinders the effective implementation of CL. For example, we present the following comments:

Moving heavy chairs and changing their arrangement in a circle was both difficult and noisy. It also took time for class, while I was worried about running out of time in class.

In my class, moving chairs was not pleasant for students (IP 7).

Each session took a lot of time to arrange the chairs, and as a result, the student's concentration was disturbed and my speech was cut off (IP 4).

But the UQ participants emphasized another challenge. They were worried about students who chose the course but did not attend class:

In my personal experience one constraint is that it has got internal students as well as external students so that means the classroom proceedings are actually recorded. You are always reminded of the students who are not in the class, but they will have access to the class recordings. So, if you do a lot of CL activities that may not be recorded, that's one of the constraints (AP 6).

If you want to do a lot of student-centred activities, then maybe the external students will be losing out on a lot of the ideas. So, you have to have some sort of balance between the needs and the demands of the students who are sitting in front of me in the class, and those who are not in the class (AP 2).

We noted at UT that moving chairs to form cooperative groups is time consuming. The students' facial expressions showed that they did not like the change of chairs from the traditional to the circular shape, because the floor of the room was not carpeted. The chairs dragged on the floor, and as a result, the noise was annoying. UQ did not face this challenge, because all classrooms were designed for teamwork.

\subsubsection{Student}

Regarding the challenges related to the student, the number of statements from the interviews was more than the observations. In this regard, the UT participants mentioned more challenges, which are mentioned in 8 quotations as examples:

In addition to society and university restrictions, some students with higher religious affiliations are reluctant to work in mixed groups by gender (IP 5).

Disorder, indecision and confusion of students in groups are the challenges of CL (IP 4).

Todays, students are not motivated. Consider I have a student whose sister has a master's degree in Education and she is unemployed. Do you think this situation 
does not affect her academic motivation? I think high motivation of students is necessary to implementing CL in university classrooms (IP 6).

Social problems and economic concerns affect students' academic motivation. In such situations, instructors and students will be less motivated to work effectively in the classroom (IP 1).

One of the disadvantages of CL is that one or two people in the group may not be allowed to talk to other members (IP 9).

Sometimes there was no opportunity to draw conclusions because some students spoke more than others in class (IP 5).

Sometimes the subject matter of the lesson was not entirely clear to the team members, and this led to non-subject matter being discussed in groups (IP 8).

Sometimes the discussions were long and non-subject matters were raised in the class (IP 3).

UQ participants attributed fewer challenges to students. They only mentioned individual differences:

Some students are very active, some students are very verbal, and other students are very shy (AP 3).

Some students say the oral English of overseas students isn't good and it has a negative effect on their assessment (AP 1).

Some students lack social skills and are not equally motivated (AP 7).

Classroom observations in UT confirm the challenges of gender, insufficient knowledge of teamwork, and the lack of student's motivation. Observations in 20 sessions show that the reason for non-curricular discussions and unequal participation of students in discussions is the ineffective implementation of CL. The challenge of students' individual differences in classroom observations at UQ was quite pronounced and, as the instructors noted, was seen in various dimensions such as academic and linguistic competencies, and social skills. Observations showed that most students were non-Australian, especially in East Asia, where there were more Chinese students.

\subsubsection{Instructor}

Instructors' challenges were similar in both universities. Instructors in interviews cited the instructor less as a challenge. Interviews implicitly and observations explicitly show that instructors are also one of the challenges in implementing CL in university classrooms. For example, classroom management and insufficient familiarity of instructors with CL were two common challenges in both universities:

In university I think the biggest challenge of CL is the fear of losing control (IP 2).

I think the only problem with CL is disrupting the classroom (AP 8). 
I see that sometimes in informal conversations the instructors mention the benefits of teamwork in the classroom, but most of them use the lecturing method in practice. While most instructors still think that group work is the same as CL (IP 7).

One of the things for instructors will be that they need more knowledge about CL. If you are not familiar with it, you don't know how to use it properly (AP 4).

First of all, there could be challenges related to the instructors. If we don't have a clear understanding of what CL is, how it works, what are the benefits and so on and so forth, defiantly we will be less willing to do it (AP 6).

Observations showed that when the instructor was talking, some students did not listen and talked to each other. In UQ, part of the class time was devoted to illustrating key concepts through power point presentations while in UT transmission approaches to teaching were more observable. Teaching in both countries was more group work than cooperative, and many of the key features of CL such as positive interdependence, individual responsibility, interpersonal skills and group processing [3] were not observable, but face-to-face interaction especially in UQ was seen in most classes, due to the circular shape of the chairs. Observations on how to implement CL in the classroom indicated that instructors were not sufficiently familiar with CL. For example, sometimes the whole class was asked to respond to a question but only one person did so. Sometimes cooperation was limited to a dyad conversing with each other. In addition, in most classes there were few opportunities for equal participation possibly because of the ineffective implementation of CL.

\subsubsection{Society}

All data regarding society as one of the challenges of CL are based on interviews. The competitive culture was a challenge in both universities with the participants using different statements to express their meaning. For example, UT participants commented:

My students and I may need to work to change the culture we have been accustomed to for years. Getting used to the culture of competition instead of cooperation is not just a problem for students, we as educators have been trained in such a system and it is a multidimensional challenge to implement interactive activities in university classrooms (IP 1).

It will be easier to implement CL in university classrooms if children are taught collaboratively from an early age (IP 9).

Because students have been accustomed to the passive method for years and have only been listeners, they resist it (IP 3).

The UQ participants responded with more emphasis and explanation:

Schools may have been taught cooperatively in year four, five, and six, but they get to year seven and suddenly the system says 'Well now we need to be competitive'. So that students who are very adept at working co-operatively, they lose it because the system now, somehow decides that it's more important to be competitive (AP 1). 
I've got students who are first year. They may have never experience CL before. I have no idea what they're come from in their secondary school environment. They might be used to individual work. Then, it takes time to create that cultural shift in terms of this is also an effective way to learn (AP 5).

I suppose in Australia there are many conflicting messages. On the one hand there is that competitive agenda, but often businesses will say 'well we want people who will be cooperative. In schools principals are looking for teachers to work in a collaborative way, but by the same token there might be rewards for success (AP 1).

We ourselves have been socialised in those terrible systems you know of grades and getting the best result. So, we too, it's in our genes. We have been socialised for so long to think that competition will deliver the best learning outcomes (AP 2).

Building positive relationships with others at the Australian society level was one of the challenges of implementing CL. AP 2 said:

I think that in society, at least here in Australia there is an increasing formal relationship.

And AP 8 said:

You look at other people and you think; 'What are they trying to get from me?' You see them as a danger, as a threat ... They get something then I miss out.

\section{Discussion}

The present case-study identified the advantages and challenges of CL through interviews and classroom observations in the University of Tehran and the University of Queensland. The current study showed that CL can provide an interactive, pleasant and safe environment for better learning in both higher education settings. Despite similar advantages in both countries, CL classes in UQ had several unique advantages: instructors engaged students in classroom discussions, made good use of classroom time, used different multimedia resources to teach, and they were motivated and even had a lot of patience and interest in talking to the observer about CL at the end of the class. Perhaps the difference in instructors' salaries between the two countries is effective in this regard, and perhaps the implementation of CL for the UQ instructors has become a motivating activity in itself [15]. This issue has various dimensions that require extensive research. However, one question remained unanswered for researchers during the observations: despite the high effort and motivation of instructors in UQ, why were the classrooms not challenging enough and students were cautious about critiquing classmates' views and even the instructor's idea? Some students did not attend classes physically but received education. Most of the attendees were also international students. Factors such as language and academic background differences, unfamiliar environment or the inconsistency of the content with students' experiences due to cultural differences may also be mentioned. Of course, these differences in the CL approach are an opportunity [34], but 
they seem to have become a challenge in our study sample. In the UT, instructors used very few multimedia resources, and the students were forthright in critiquing and challenging the views of the instructor and their classmates, but it seems that UT instructors, like their colleagues in UQ, were concerned about the time constraints, and as a result, the discussions and conclusions remained incomplete. Accordingly, we suggest that instructors consider reducing the volume of course content and devote more time to teamwork and evaluating reports.

The appropriate learning environment, which was mentioned in the present study as an advantage of CL, provides a suitable environment for deep learning [10]. Deep learning and solving complex problems was the second advantage of CL that was mentioned by participants from both universities. Previous studies [5,6] also support these results. Results from both settings showed that CL creates more opportunities for thinking, and leads to the development of knowledge. The review of the literature indicates that CL is also used to reinforce critical thinking skills [7], and to provide a safe environment for the construction of knowledge [11]. However, despite many advantages of $\mathrm{CL}$ that were reported in the present study further research needs to be undertaken in other academic disciplines. UQ instructors referred to the advantages of CL more than UT instructors (Table 1). We did not explore the cause of this difference in this study. This may be a topic for future research.

Insufficient time and grading were two major challenges of CL in both universities. Although some studies have considered insufficient time as a challenge for CL [26,27], it seems that by effective implementation of CL, time can be saved. In this case, the role of assessment can be reduced and individual and group performance during the semester can be emphasized instead of the current assessment system. Of course, in Iran, instructors must teach based on a predetermined syllabus and evaluate student performance based on a 0-20 grading system. In such a system it is difficult but not impossible to implement CL. Observations from five classes showed that although instructors in UQ used class time effectively, because of the large number of students in the classroom, there was little opportunity to discuss and critique group reports. In this regard, Emmer and Evertson [29] reported that there is more opportunity for interaction and participation in small classrooms.

Restricted seating arrangement in UT was an obvious challenge as the disruption caused by moving the chairs may be annoying. Higher education planners need to consider the requirements of CL in designing and constructing educational spaces as well as purchasing appropriate classroom equipment so it can be implemented effectively.

Changing course in UQ was as much a challenge as the stability of rules in Iran! It seems that in the present age, higher education curricula should emphasize skills such as adapting to changes. Skills such as communicative skills [8] that are enhanced through CL can potentially help students adapt to these changes.

Based on our findings in UQ, some students chose the course but did not attend in the class. They could access the content recorded in the classroom. They missed student-centred activities such as group work, and live talks which is emphasized by Gillies 
[12], and instructors had to adjust the method to be useful to all students. To overcome this challenge, external students' classrooms could be formed separately, enabling instructors to conduct the class through the e-learning system from their office. Of course, the basic question is how we can implement CL in an online environment. This is an important and very interesting topic for future research.

The results of our study showed that in UT because of the religious beliefs, it was not possible to form heterogeneous groups in terms of gender, and this is while Nguyen-Phuong-Mai [34] sees heterogeneity as an opportunity to increase the productivity of teamwork. In UT as well, students lacked academic motivation. They also had little information about how teamwork works in the classroom. Although this challenge can be explored in future research but, in line with Sanaie, Vasli, Sedighi, and Sadeghi [9], we believe that CL can be effective in increasing students' academic motivation by providing a better environment for learning. In addition, students can become practically acquainted with CL while working as a team, and overcome the lack of cooperative skills that Le and Wubbels [28] cites as a challenge. It seems the reason for some of the challenges, such as the non-curriculum discussions, is the ineffective implementation of CL which confuses students and leads them to non-curriculum topics, and that probably creates a challenge called "classroom management." The challenge faced by instructors in both universities. We infer from the challenges identified in this study that if the instructors were fully acquainted with CL, they would have implemented this approach better, and as a result, the challenges would have been minimized. Therefore, it seems that challenges are related to the quality of CL implementation, not the nature of CL. As Gillies [13] points out when instructors implement CL effectively, students learn how to dialogue and ask questions, make clear their ideas, and assess the issues they are arguing.

Our study showed that competitive culture in both countries is a great challenge of CL. Overcoming this challenge is not as easy as other challenges, because it is out of the instructor's control. We think that teaching approaches must be reformed in the kindergarten, primary and secondary schools, because young people who grow up with cooperative culture will be more prepared to work in teams in university classrooms.

The UQ has students from many different cultures and this heterogeneity is a unique opportunity to effectively implementation of CL [34] in UQ classrooms. Perhaps by effective implementing CL in the classroom, students can be introduced to different cultures, thereby strengthening the relationships between students and expanding mutual trust between them. However, the challenge of building positive relationships with others could show us a new topic for research in Australian.

In this study, the frequency of referring to challenges was more than advantages (Table 2). This result may indicate that there is a strong tendency to prepare the conditions for CL. There were many similarities between the two universities in terms of curriculum, instructor and society challenges, but there were basic differences in terms of student challenges. Students at the UT are accepted as the largest university in Iran based on a high national competition and the number of international students is very low, while at the UQ in Australia the selection system is different and the number of interna- 
tional students is very high. This is not an exact explanation of this difference and we need more studies in the international level in this field.

This study had four main limitations: Firstly, in both universities, we selected instructors who stated that they use a CL approach and would like to participate in interviews. There may be classes where CL is implemented and we have not been able to involve them in our study. Secondly, group activities in the classroom are a prerequisite for the implementation of CL and can provide the context for the implementation of it, but these activities are not necessarily cooperative. During the study, we found that activities performed in the name of $C L$ are closer to group work than cooperative group work. We believe that if instructors in both universities were fully familiar with CL, they would have implemented this approach more fully in the classroom. As a result, we were able to better identify the advantages and challenges. Thirdly, because interviewer and observer was a non-Australian, the English language problem could be a limitation in conducting interviews and observations. Fourthly, the presence of a colleague observer in the classroom may affect the instructor's natural teaching. This limitation was more evident in classroom observations at the UT, because the observer was a full-time faculty member at the UT.

\section{Conclusions and Implications}

This study revealed similarities and differences in two different cultures and showed that CL should be understood as a useful teaching-learning approach in higher education. In this study, we reported on some of the advantages of CL from the instructors and we observed some of these in the classrooms. Simultaneously, we found that instructors as well as students in the field of Education are not fully familiar with the CL approach. Based on this, we believe that familiarity of instructors with CL can have positive outcomes for students. Instructors in both universities attributed most of the challenges to the curriculum, the student, and the society, but when we analysed the interview data alongside the observations, we found that some of the challenges could be overcome by introducing CL to instructors to help improve the quality of CL implementation in the classroom, for example, addressing issues such as: seating arrangements, allocating time to respond to team reports, and familiarising students with the philosophy and skills of working in groups. These are skills that are essential for the effective implementation of CL [29]. Instructors do not learn how to implement CL; they need to have opportunities to participate in professional development workshops that provide them with the background knowledge and training needed to implement it effectively in their classes. This study has following implications:

* University administrators try to familiarize faculty members with a CL approach through workshops and training courses.

* University administrators and faculty members are introduced to the advantages and challenges of CL and use the experience of implementing CL internationally.

* University administrators prepare for the potential challenges of CL and can provide 
prerequisites for implementation before it can be implemented by instructors.

* Faculty members are interested in CL and motivate to familiarize their students with the philosophy of teamwork and how to work in groups before performing it in the classroom.

* Faculty members understand how to implement CL to promote students learning.

Conflicts of Interest: The author declares no conflict of interest.

Funding: This research received no external funding.

Informed Consent Statement: Informed consent was obtained from all subjects involved in the study.

Acknowledgments: We thank the faculty members of the School of Education at the University of Queensland, as well as the faculty members of the faculty of Psychology and Education at the University of Tehran, who volunteered to participate in the interviews and allowed their classroom to be observed.

\section{References}

1. Ghaith, G.M. Teacher perceptions of the challenges of implementing concrete and conceptual cooperative learning. Issues in Educational Research. 2018, 28(2):385. doi:10.13140/RG.2.2.32014.66888

2. Slavin, R.E.; Cooper, R. Improving intergroup relations: lessons learned from cooperative learning programs. Journal of Social Issues. 1999, 55(4), 647-663. doi:10.1111/0022-4537.00140

3. Johnson, D.W.; Johnson, R.T. An educational psychology success story: Social interdependence theory and cooperative learning. Educational Researcher. 2009, 38(5), 365-379. doi:10.3102/0013189X09339057

4. Van Ryzin, M.J.; Roseth, C.J. Cooperative learning in middle school: A means to improve peer relations and reduce victimization, bullying, and related outcomes. Journal of educational psychology. 2018, 110(8):1192. doi:10.1037/edu0000265

5. Cámara-Zapata, J.M.; Morales, D. Cooperative learning, student characteristics, and persistence: an experimental study in an engineering physics course. European Journal of Engineering Education. 2020, 45(4):565-77. doi:10.1080/03043797.2019.1569593

6. O'Connor, C.; Michaels, S.; Chapin, S.; Harbaugh, A.G. The silent and the vocal: Participation and learning in whole-class discussion. Learning and Instruction. 2017, 48:5-13. doi:10.1016/j.learninstruc.2016.11.003

7. Erdogan F. Effect of cooperative learning supported by reflective thinking activities on students' critical thinking skills. Eurasian Journal of Educational Research. 2019, 80:89-112. doi:10.14689/ejer.2019.80.5

8. Dendup, T.; Onthanee A. Effectiveness of cooperative learning on English communicative ability of 4 th grade students in Bhutan. International Journal of Instruction. 2020, 13(1):255-66. doi:10.29333/iji.2020.13117a

9. Sanaie, N.; Vasli, P.; Sedighi, L.; Sadeghi, B. Comparing the effect of lecture and Jigsaw teaching strategies on the nursing students' self-regulated learning and academic motivation: A quasi-experimental study. Nurse education today. 2019, 79:35-40. doi:10.1016/j.nedt.2019.05.022

10. Barksdale, C.; Peters, M.L.; Corrales, A. Middle school students' perceptions of classroom climate and its relationship to achievement. Educational Studies. 2019, 11:1-24. doi:10.1080/03055698.2019.1664411

11. Eryilmaz, M.; Cigdemoglu, C. Individual flipped learning and cooperative flipped learning: their effects on students' performance, social, and computer anxiety. Interactive Learning Environment. 2019, 27(4), 432-442. doi:10.1080/10494820.2018.1522652

12. Gillies, R. Dialogic Teaching during Cooperative Inquiry-Based Science: A Case Study of a Year 6 Classroom. Educ. Sci. 2020, 10, 328. doi:10.3390/educsci10110328

13. Gillies, R. Cooperative learning: Review of research and practice. Australian Journal of Teacher Education. 2016, 41(3):3. doi:10.14221/ajte.2016v41n3.3

14. Sumtsova, O.; Aikina, T.; Bolsunovskaya, L.; Phillips, C.; Zubkova, O.; Mitchell, P. Collaborative learning at engineering universities: Benefits and challenges. International Journal of Emerging Technologies in Learning (iJET). 2018, 13(1):160-77. doi:10.3991/ijet.v13i01.7811

15. Kohn, A. Punished by rewards; Houghton Mifflin Harcourt: Boston, New York, 2018.

16. Gisbert, D.D.; Seuba, M.C.; Coll, M.F. Enhancing expectations of cooperative learning use through initial teacher training. International Journal of Educational Psychology. 2017, 6(3):278-300. doi:10. 17583/ijep.2017.2504

17. Swanson, E.; McCulley, L.V.; Osman, D.J.; Scammacca, L.N.; Solis, M. The effect of team-based learning on content knowledge: A meta-analysis. Active learning in higher education. 2019, 20(1):39-50. doi:10.1177/1469787417731201 
18. Gillies, R.; Nichols K. How to support primary teachers' implementation of inquiry: Teachers' reflections on teaching cooperative inquiry-based science. Research in Science Education. 2015, 45(2):171-91. (2), 171-191. doi:10.1007/s11165-014-9418-x

19. Ferguson-Patrick, K. Cooperative learning in Swedish classrooms: Engagement and relationships as a focus for culturally diverse students. Education Sciences. 2020, 10(11):312.

20. Chen, R.H. Fostering students'workplace communicative competence and collaborative mindset through an inquiry-based learning design. Educ. Sci. 2021, 11, 17. doi: 10.3390/educsci11010017

21. Kimmelmann, N.; Lang J. Linkage within teacher education: cooperative learning of teachers and student teachers. European Journal of Teacher Education. 2019, 42(1):52-64. doi: 10.1080/02619768.2018.1547376

22. Abercrombie, S.; Hushman, C.J.; Carbonneau, K.J. The influence of timing of peer cooperation on learning. Educational Psy-chology. 2019, 39(7), 881-99. doi:10.1080/01443410.2019.1567690

23. Gillies, R.; Boyle M. Teachers' reflections on cooperative learning: Issues of implementation. Teaching and Teacher Education. 2010, 26 (4) 933-940. doi:10.1016/j.tate.2009.10.034

24. De Hei, M.S.; Strijbos, J.W.; Sjoer, E.; Admiraal, W. Collaborative learning in higher education: lecturers' practices and beliefs. Research Papers in Education. 2015 , 30(2):232-47. doi:10.1080/02671522. 2014.908407

25. Nokes-Malach, T.J.; Richey, J.E.; Gadgil, S. When is it better to learn together? Insights from research on collaborative learning. Educational Psychology Review. 2015, 27(4):645-56. doi:10.1007/s10648-015-9312-8

26. Buchs, C.; Filippou, D.; Pulfrey, C.; Volpé Y. Challenges for cooperative learning implementation: Reports from elementary school teachers. Journal of education for teaching. $2017,43(3): 296-306$. doi:10.1080/02607476.2017. 1321673

27. Lumpe, A.T.; Haney, J.J.; Czerniak, C.M. Science teacher beliefs and intentions regarding the use of cooperative learning. School Science and Mathematics. 1998 , 98(3):123-35. doi:10.1111/j.1949-8594. 1998.tb17405.x

28. Le H, J.J.; Wubbels T. Collaborative learning practices: teacher and student perceived obstacles to effective student collaboration. Cambridge Journal of Education. 2018, 48(1):103-22. doi:10.1080/0305764X.2016. 1259389

29. Emmer, E. T.; Evertson, C. M. Classroom Management for Middle and High School Teachers; Upper Saddle River, NJ: Pearson, 2013.

30. Scardamalia, M.; Bereiter, C. Knowledge building: Theory, Pedagogy, and Technology. In K. Sawyer (Ed.), Cambridge handbook of the learning sciences (pp. 97-118); New York: Cambridge University Press. 2006.

31. Hakkarainen, K. A. knowledge-practice perspective on technology-mediated learning. International Journal of Computer-Supported Collaborative Learning. 2009, 4(2):213-31. doi:10.1007/s11412-009-9064-x

32. Qiu, M.; Hewitt, J.; Brett, C. Online class size, note reading, note writing and collaborative discourse. International Journal of Computer-Supported Collaborative Learning. 2012, 7(3):423-42. doi:10.1007/s11412-012-9151-2

33. Völlinger, V.A.; Supanc, M. Student teachers' attitudes towards cooperative learning in inclusive education. European Journal of Psychology of Education. 2020, 35:1-23. doi:10.1007/s10212-019-00435-7

34. Nguyen-Phuong-Mai, M. Culturally appropriate face strategies in cooperative learning with insight from cultural neuroscience. Comparative Education. 2019, 55(1):66-96. doi:10.1080/03050068.2018.1541664

35. Chiu, P.H.; Cheng, S.H. Effects of active learning classrooms on student learning: a two-year empirical investigation on student perceptions and academic performance. Higher Education Research \& Development. 2017, 36(2):269-79. doi:10.1080/07294360.2016.1196475

36. Gillies, R. Promoting thinking, problem-solving and reasoning during small group discussions. Teachers and Teaching: theory and practice. 2011, 17(1):73-89. doi:10.1080/13540602.2011.538498

37. Volet, S.; Mansfield, C. Group work at university: significance of personal goals in the regulation strategies of students with positive and negative appraisals. Higher Education Research \& Development. 2006, 25(4), 341-356. doi:10.1080/07294360600947301

38. Alburaidi, A.; Ambusaidi, A. The impact of using activities based on the Montessori approach in science in the academic achievement of fourth grade students. International Journal of Instruction. 2019, 12(2):695-708. doi:10.29333/iji.2019.12244a

39. Hussien, A.M. The impact of combining communicative traits of writing with cooperative learning on trainee teachers' pedagogical knowledge and attitudes. International Journal of Instruction. 2020, 13(1):813-930. doi:10.29333/iji.2020.13152a

40. Sutarman, S. D.; Mulyati, Y. Investigating cooperative learning model based on interpersonal intelligence on language learners skill to write article. International Journal of Instruction. 2019, 12(4):201-18. doi:10.29333/iji.2019.12413a

41. Tran, V.D. Does cooperative learning increase students' motivation in learning? International Journal of Higher Education. 2019, 8(5):12-20. doi:10.5430/ijhe.v8n5p12

42. Aldridge, J. M.; Fraser, B. J.; Huang, T. C. I. Investigating classroom environments in Taiwan and Australia with multiple research methods. The Journal of Educational Research. 1999, 93(1), 48-62. doi:10.1080/00220679909597628.

43. Spradely, J. P. Participant Observation; Fort Worth, TX: Harcourt Brace. 1980.

44. Anderson, L. Analytic autoethnography. Journal of contemporary ethnography. 2006, 35(4):373-95. doi:10.1177/0891241605280449.

45. Cohen, L.; Manion, L.; Morrison, K. Research Methods in Education; Oxon: Rutledge, 2018. 